\title{
Front Matter: Volume 8194
}

, "Front Matter: Volume 8194," Proc. SPIE 8194, International Symposium on Photoelectronic Detection and Imaging 2011: Advances in Imaging Detectors and Applications, 819401 (18 August 2011); doi: 10.1117/12.905273

SPIE Event: International Symposium on Photoelectronic Detection and Imaging 2011, 2011, Beijing, China 


\title{
PROCEEDINGS OF SPIE
}

International Symposium on Photoelectronic Detection and Imaging 2011

\section{Advances in Imaging Detectors and Applications}

\author{
Makoto Ikeda \\ Nanjian Wu \\ Guangjun Zhang \\ Kecong Ai \\ Editors
}

\section{4-26 May 2011 \\ Beijing, China}

\section{Organized by}

Photoelectronic Technology Professional Committee, CSA (China)

Tianjin Jinhang Institute of Technical Physics, CASIC (China)

Science and Technology on Low Light Level Night Vision Laboratory (China)

Sponsored by

Chinese Society of Astronautics (China) 
The papers included in this volume were part of the technical conference cited on the cover and title page. Papers were selected and subject to review by the editors and conference program committee. Some conference presentations may not be available for publication. The papers published in these proceedings reflect the work and thoughts of the authors and are published herein as submitted. The publisher is not responsible for the validity of the information or for any outcomes resulting from reliance thereon.

Please use the following format to cite material from this book:

Author(s), "Title of Paper," in International Symposium on Photoelectronic Detection and Imaging 2011: Advances in Imaging Detectors and Applications, edited by Makoto Ikeda, Nanjian Wu, Guangjun Zhang, Kecong Ai, Proceedings of SPIE Vol. 8194 (SPIE, Bellingham, WA, 2011) Article CID Number.

ISSN 0277-786X

ISBN 9780819488350

Published by

SPIE

P.O. Box 10, Bellingham, Washington 98227-0010 USA

Telephone +1 3606763290 (Pacific Time) · Fax +1 3606471445

SPIE.org

Copyright () 2011, Society of Photo-Optical Instrumentation Engineers

Copying of material in this book for internal or personal use, or for the internal or personal use of specific clients, beyond the fair use provisions granted by the U.S. Copyright Law is authorized by SPIE subject to payment of copying fees. The Transactional Reporting Service base fee for this volume is $\$ 18.00$ per article (or portion thereof), which should be paid directly to the Copyright Clearance Center (CCC), 222 Rosewood Drive, Danvers, MA 01923. Payment may also be made electronically through CCC Online at copyright.com. Other copying for republication, resale, advertising or promotion, or any form of systematic or multiple reproduction of any material in this book is prohibited except with permission in writing from the publisher. The CCC fee code is $0277-786 \mathrm{X} / 11 / \$ 18.00$.

Printed in the United States of America.

Publication of record for individual papers is online in the SPIE Digital Library.

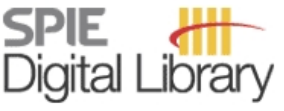

SPIEDigitalLibrary.org

Paper Numbering: Proceedings of SPIE follow an e-First publication model, with papers published first online and then in print and on CD-ROM. Papers are published as they are submitted and meet publication criteria. A unique, consistent, permanent citation identifier (CID) number is assigned to each article at the time of the first publication. Utilization of CIDs allows articles to be fully citable as soon as they are published online, and connects the same identifier to all online, print, and electronic versions of the publication. SPIE uses a six-digit CID article numbering system in which:

- The first four digits correspond to the SPIE volume number.

- The last two digits indicate publication order within the volume using a Base 36 numbering system employing both numerals and letters. These two-number sets start with $00,01,02,03,04$, $05,06,07,08,09,0 A, 0 B \ldots 0 Z$, followed by 10-1Z, 20-2Z, etc.

The CID number appears on each page of the manuscript. The complete citation is used on the first page, and an abbreviated version on subsequent pages. Numbers in the index correspond to the last two digits of the six-digit CID number. 


\section{Contents}

\section{Part One}
xv Symposium Committee
xvii Conference Committee
xix Introduction
xxi Cooperating Organizations

\section{ADVANCES IN IMAGING DETECTORS AND APPLICATIONS}

819402 A CMOS imager with negative feedback pixel circuits and its applications [8194-01] M. Ikebe, J. Motohisa, Hokkaido Univ. (Japan)

819403 Solid state photon counters and their applications in space related projects [8194-02] I. Prochazka, J. Blazej, J. Kodet, Czech Technical Univ. in Prague (Czech Republic)

819404 Research on the two-dimension performance model for human eye [8194-03] K. Ai, Xi'an Institute of Applied Optics (China) and Science and Technology on Low-Light-Level Night Vision Lab. (China)

819405 Infrared nonuniformity correction and radiometric calibration technology using U-shaped blackbody [8194-04]

W. Jin, C. Liu, J. Xiu, Beijing Institute of Technology (United States)

819406 Research on photoluminescence of membrane layer of $\mathrm{Na}_{2} \mathrm{KSb}$ antimony-alkali compound [8194-05]

X. Li, North Night Vision Science and Technology Group Co., Ltd (China); F. Yu, Yunnan Univ. (China); K. Song, Y. Qian, J. Tan, W. Yan, North Night Vision Science and Technology Group Co., Ltd (China)

819407 Fabrication of a bulk conductive glass microchannel plate [8194-06] J. Pan, Changchun Univ. of Science and Technology (China) and North Night Vision Technology Group Corp. (China); J. Lv, T. Zheng, Changchun Univ. of Science and Technology (China); Y. Li, W. Xu, North Night Vision Technology Group Corp. (China)

819408 Processing and analyzing transmission electron microscope images of nanocrystals [8194-07]

X. Yang, North China Electric Power Univ. (China)

819409 Image fusion base on improved contourlet transform [8194-08]

L. Wang, Shenzhen Univ. (China) and Soochow Univ. (China); C. Li, X. Zhao, Soochow Univ. (China); X. Liu, Shenzhen Univ. (China)

8194 OA The algorithm of motion blur image restoration based on PSF half-blind estimation [8194-09] D. Chen, Z. Lin, Beijing Institute of Space Mechanics \& Electricity (China) 
8194 OC Adjustment-based data fusion method in the pose relay videometric using camera network [8194-11]

Z. Chao, National Univ. of Defense Technology (China) and Hunan Key Lab. for Image Measurement and Vision Navigation (China); Q. Yu, Hunan Key Lab. for Image Measurement and Vision Navigation (China) and National Univ. of Defense Technology (China); S. Fu, G. Jiang, National Univ. of Defense Technology (China) and Hunan Key Lab. for Image Measurement and Vision Navigation (China)

8194 OD Research on shutter mode of CMOS imager and its application [8194-12] D. Liu, Z. Liu, W. Sun, J. Zhang, Changchun Univ. Science and Technology (China)

8194 OE Fabric defects identification based on on-line 3D measurement [8194-13] L. Song, H. An, X. Dong, C. Zhang, TianJin Polytechnic Univ. (China)

8194 OF The study of color image defogging based on wavelet transform and single scale retinex [8194-14]

M. Wang, S. Zhou, F. Huang, Z. Liu, H. Bai, PLA Univ. of Science and Technology (China)

8194 OG Experimental investigation on silicon microchannel plate electron multiplier [8194-15] Q. Duanmu, G. Wang, Y. Li, Y. Wang, H. Cheng, X. Qin, Z. Jiang, D. Jiang, Changchun Univ. of Science and Technology (China)

$8194 \mathrm{OH} \quad$ Analysis on short-range millimetre wave scattering imaging system [8194-16] L. Zhu, X.-G. Li, G.-W. Lou, C. Zhang, Nanjing Univ. of Science and Technology (China)

$8194 \mathrm{Ol} \quad$ A new code flag method based on coordinate quadrant in vision measurement [8194-17] L. Song, C. Zhang, Y. Wei, X. Dong, H. An, Tian Jin Polytechnic Univ. (China)

$81940 \mathrm{~J} \quad$ Research on optical properties of transmission-mode GaAs photocathode module [8194-18]

J. Zhao, Y. Xiong, B. Chang, Y. Zhang, J. Zhang, Nanjing Univ. of Science and Technology (China)

8194 OK Research of BRDF effects on remote sensing imagery [8194-19] P. Nina, W. Kun, L. Tao, P. Yang, Beijing Institute of Space Mechanics \& Electricity (China)

8194 OL Design of 300 frames per second 16-port CCD video processing circuit [8194-20] S. Yang, M. Guo, B. Li, J. Xia, Q. Wang, Northwest Institute of Nuclear Technology (China)

8194 OM Development of 4kx4k long-range digital imaging system [8194-21]

M. Guo, Q. Wang, S. Yang, J. Xia, F. Sun, Northwest Institute of Nuclear Technology (China); C. Liu, Qinshan Nuclear Power Co., Ltd. (China)

8194 ON Photoemission performance of gradient-doping transmission-mode GaAs photocathodes [8194-22]

Y. Zhang, Nanjing Univ. of Science \& Technology (China); J. Niu, Nanjing Univ. of Science \& Technology (China) and Nanyang Institute of Technology (China); J. Zou, Y. Xiong,

B. Chang, J. Zhang, Y. Du, Nanjing Univ. of Science \& Technology (China) 
819400 The research on and application of detecting technology in car intelligent video-aided driving system [8194-23]

Y. Chen, L. Sun, C. Lu, Guilin Univ. of Electronic Technology (China)

8194 OP Pipeline structure for real-time centroid calculation of Hartmann wavefront sensor with horizontal multi-channel pixel output [8194-24]

S. Wang, Institute of Optics and Electronics (China) and The Key Lab. on Adaptive Optics (China) and Graduate Univ. of Chinese Academy of Sciences (China); C. Wang, C. Rao, Institute of Optics and Electronics (China) and The Key Lab. on Adaptive Optics (China)

$81940 Q$ The theory studies and simulation of optical rotation of uniaxial crystal particle [8194-25] Y. Y. Zhu, Y. Wei, J. F. Shen, Y. T. Li, H. X. Dou, Yanshan Univ. (China)

8194 OR The research on statistical properties of TDI-CCD imaging noise [8194-26] Y. Gu, Changchun Institute of Optics, Fine Mechanics and Physics (China) and Graduate Univ. of Chinese Academy of Sciences (China); X. Shen, G. He, Changchun Institute of Optics, Fine Mechanics and Physics (China)

8194 OS Real-time distortion correction system of large-field optical display equipment based on FPGA [8194-27]

C. Zheng, Y. Zhou, Science and Technology on Electro-optic Control Lab. (China) and Luoyang Institute of Electro-Optical Equipment (China); Y. Zheng, J. Li, Luoyang Institute of Electro-Optical Equipment (China)

8194 OT Reverse engineering of the homogeneous-entity product profiles based on CCD [8194-28] Y. Gan, J. Zhong, N. Sun, A. Sun, Guilin Univ. of Electronic Technology (China)

$8194 \mathrm{OU}$ The three-dimensional measurement research of aero-engine blade based on structured light [8194-29]

Y. Fu, M. Wan, Nanchang Hangkong Univ. (China)

8194 OV Change detection of multi-temporal remote sensing images based on multi-band KL transform [8194-30]

Y. Chen, X. Zhao, Shenzhen Univ. (China) and Soochow Univ. (China); X. Liu, Shenzhen Univ. (China)

8194 OW High dynamic range color imaging with a camera based on piecewise color characterization [8194-31]

B. Tan, N. Liao, Y. Lian, L. Tian, W. Wu, Beijing Institute of Technology (China)

8194 OX Vision measurement method of object position in large remote area [8194-32] M. Liu, Beijing Technology and Business Univ. (China) and Beijing Institute of Technology (China); K. Li, H. Cai, W. Zhu, Beijing Institute of Technology (China)

8194 OY Camouflaged target detection based on visible and near infrared polarimetric imagery fusion [8194-33]

P. Zhou, F. Wang, H. Zhang, M. Xue, Hefei New Star Applied Technology Research Institute (China) 
$8194 \mathrm{OZ}$ Research on $0.1 \mathrm{THz}$ alternating current radiometric security inspection imaging for antiterrorism application [8194-34]

G. Zhang, W. Qin, G. Lou, Nanjing Univ. of Science and Technology (China)

819410 Multi-focus image fusion algorithm based on adaptive PCNN and wavelet transform [8194-35]

Z. Wu, M. Wang, G. Han, Changchun Institute of Optics, Fine Mechanics and Physics (China)

819411 Design of high-speed driving circuit for large area array full frame transfer CCD [8194-36]

Y. Wang, Z. He, Beijing Institute of Space Mechanics and Electricity (China)

819412 The research of polarization image fusion method based on modulation in multi-scale space [8194-37]

L. Xiao, Anhui Institute of Optics and Fine Mechanics (China) and Electronic Engineering Institute (China); W. Feng, New Star Research Institute of Applied Technology (China)

819413 Stray light and its reduction of focal plane arrays [8194-38]

C. Yu, J. Zhou, R. Shi, W. Shen, Soochow Univ. (China)

819414 A new method of focal plane mosaic for space remote sensing camera [8194-39]

G. Sun, L. Li, Beijing Institute of Technology (China)

819415 The x-ray imaging system's requirements for CCD pixel [8194-40]

C. Yu, Peking Univ. Shenzhen Graduate School (China) and Nanjing Univ. of Posts and Telecommunication (China); L. Kong, Shenzhen Invengo Information Technology Co., Ltd. (China); J. Zhang, Nanjing Univ. of Science and Technology (China); C. He, S. Zhang, Peking Univ. Shenzhen Graduate School (China)

819416 Detection research on low light level target with joint transform correlator [8194-41] S. Zhang, J. Shang, C. Chen, W. Wang, Changchun Univ. of Science and Technology (China)

819417 A practical method to extending dynamic range of CCD camera [8194-42] Z. Chen, Xi'an Institute of Optics and Precision Mechanics (China) and Graduate Univ. of Chinese Academy of Sciences (China); Y. Qiu, Y. Wen, B. Jiang, B. Gao, Xi'an Institute of Optics and Precision Mechanics (China)

819418 Monocular visual odometry based on inverse perspective mapping [8194-43] Y. Cao, Y. Feng, Y. Yang, Y. Chen, B. Lei, L. Zhao, National Univ. of Defense Technology (China)

819419 Ground moving target geo-location from monocular camera mounted on a micro air vehicle [8194-44]

L. Guo, H. Ang, X. Zheng, Nanjing Univ. of Aeronautics and Astronautics (China)

$81941 \mathrm{~A}$ The research on the moiré fringe image preprocessing [8194-45]

X. Xiao, M. Ao, C. Yang, R. Yang, Univ. of Electronic Science and Technology of China (China)

8194 1B Vision-based multiple vehicle detection and tracking at nighttime [8194-46]

W. Xu, H. Liu, Shandong Univ. At Weihai (China) 
8194 1C Improvement for exposure time measurement of the microchannel plate gated framing camera [8194-47]

H. Cai, Tianjin Univ. (China) and Shenzhen Univ. (China); J. Liu, Shenzhen Univ. (China); X. Peng, Tianjin Univ. (China) and Shenzhen Univ. (China); L. Niu, W. Peng, L. Gu, J. Long, Shenzhen Univ. (China)

8194 1D Monte Carlo simulation for x-ray detector [8194-48]

H. Cai, Tianjin Univ. (China) and Shenzhen Univ. (China); J. Liu, Shenzhen Univ. (China); X. Peng, Tianjin Univ. (China) and Shenzhen Univ. (China); L. Niu, W. Peng, J. Long, Shenzhen Univ. (China)

8194 1E Computation for polarizer's optimal rotation angle on airborne optical platform [8194-49] B. Feng, Shenyang Institute of Automation (China) and Graduate School of the Chinese Academy of Sciences (China) and Key Lab. Opto-Electronic Information Processing (China); Z. Shi, Shenyang Institute of Automation (China) and Key Lab. Opto-Electronic Information Processing (China); Q. Ding, Research Institute of General Development and Demonstration of Equipment (China); X. Yu, Avic Hongdu Aviation Industry Group Ltd. (China)

$8194 \mathrm{lF} \quad$ An autonomous low-power high-resolution micro-digital sun sensor [8194-50] N. Xie, Technische Univ. Delft (Netherlands); A. J. P. Theuwissen, Technische Univ. Delft (Netherlands) and Harvest Imaging (Belgium)

$81941 G \quad$ Research on surface free energy of electrowetting liquid zoom lens [8194-52] C. Zhao, G. Lu, D. Wei, Luoyang Normal Univ. (China); X. Hong, Henan Institute of Science and Technology (China); D. Cui, C. Gao, Luoyang Normal Univ. (China)

$81941 \mathrm{H} \quad$ A digital auto-focusing method based on CCD mosaicing for aerial camera [8194-53] Y. Wang, Y. Liu, X. Chen, Harbin Institute of Technology (China)

819411 The MCP dynamic characteristics with different bias voltage [8194-54] H. Cai, Shenzhen Univ. (China) and Tianjin Univ. (China); J. Liu, Shenzhen Univ. (China); X. Peng, Shenzhen Univ. (China) and Tianjin Univ. (China); L. Niu, W. Peng, J. Long, Shenzhen Univ. (China)

$81941 \mathrm{~J} \quad$ An imaging geometry model of space camera [8194-55]

Z. Zhang, Z. Liu, Beijing Institute of Space Mechanics and Electricity (China)

$81941 \mathrm{~K}$ Research on computer tracking system of uniaxial tension based on image correlation method [8194-56]

W. Wang, Nanjing Institute of Technology (China); X. He, Southeast Univ. (China)

8194 1L A relative radiometric correction method for linear array push-broom imagery [8194-57] H. Li, H. Song, Beijing Institute of Satellite Information Engineering (China)

$81941 \mathrm{M}$ The low light level image intensifier's application in $\mathbf{x}$-ray imaging [8194-58]

C. Yu, Peking Univ. Shenzhen Graduate School (China) and Nanjing Univ. of Posts and Telecommunication (China); L. Kong, Shenzhen Invengo Information Technology Co., Ltd. (China); J. Zhang, Nanjing Univ. of Science and Technology (China); S. Zhang, Peking Univ. Shenzhen Graduate School (China) 
$81941 \mathrm{~N}$ The imaging system design of three-line LMCCD mapping camera [8194-59] H.-D. Zhou, J.-G. Liu, X.-X. WU, S.-L. LV, Y. Zhao, Changchun Institute of Optics, Fine Mechanics and Physics (China); D. Yu, Changchun Institute of Optics, Fine Mechanics and Physics (China) and Graduate School of the Chinese Academy of Science (China)

819410 Long focal length large-aperture switch-zoom system design [8194-60] Y. Wang, J. Duan, H. Jin, K. Jiang, H. Zhang, Xi'an Institute of Optics and Precision Mechanics (China)

8194 IP Measuing the steel tensile deformation based on linear CCD [8194-61] L. Deng, W. Liang, X. Fan, T. XU, H. Yang, L. Chen, D. Chen, Y. Liu, Univ. of Electronic Science and Technology of China (China)

$81941 Q \quad$ XPS study on microporous surface composition of microchannel plates [8194-62] Y. Huang, Y. Zhang, H. Liu, Z. Gu, China Building Materials Academy (China)

8194 IR Real-time low-light-level image enhancement algorithm applies to FPGA [8194-63] S. Tian, Ningbo Dahongying Univ. (China); Y. Tian, Guizhou Univ. (China); J. Jue, Ningbo Dahongying Univ. (China)

8194 is Research on inside surface of hollow reactor based on photoelectric detecting technique [8194-64]

G. Song, Y. Na, W. Shi, Q. Zhang, Changchun Univ. of Science and Technology (China)

$81941 \mathrm{~T}$ The research of the application of the computer vision on the non-contacted body measurement based on the improved ant colony algorithm in the body type clustering [8194-65]

Q. Zhan, Anhui Agriculture Univ. (China); N. Zhao, Hefei Electronic Engineering Institute (China)

$81941 \mathrm{U}$ Multispectral imaging utilizing LCTF technology for plant disease detection [8194-66] L. Tian, N. Liao, Beijing Institute of Technology (China); A. Chai, Chinese Academy of Agricultural Sciences (China); B. Tan, D. Cui, J. Wang, Beijing Institute of Technology (China)

8194 IV Light decreases through the x-ray imaging chain [8194-67]

C. Yu, Peking Univ. Shenzhen Graduate School (China) and Nanjing Univ. of Posts and Telecommunication (China); L. Kong, Shenzhen Invengo Information Technology Co., Ltd. (China); J. Zhang, Nanjing Univ. of Science and Technology (China); S. Zhang, Peking Univ. Shenzhen Graduate School (China)

$8194 \mathrm{lW}$ Measurement and analysis of signal to noise ratio for image intensifier tube, $18 \mathrm{~mm}$ microchannel plate [8194-68]

X. Bai, F. Shi, National Key Lab. of Science and Technology on Low Light Level Night Vision (China) and North Night Vision Technology Co., Ltd. (China); H. Feng, Northwest Institute of Nuclear Technology (China); R. Liu, Xi'an Technological Univ. (China); L. Yin, Y. He, National Key Lab. of Science and Technology on Low Light Level Night Vision (China) and North Night Vision Technology Co., Ltd. (China)

$81941 \mathrm{X}$ Performance simulation of dual-band IR imaging detector based on MATLAB [8194-69]

L. Zhang, H. Chen, Luoyang Optoelectronic Technology Development Ctr. (China) 
$81941 Y$ Research on gas within transformer oil based on photo-spectroscopy technology [8194-70] G. Song, Y. Na, Q. Zhang, W. Shi, Changchun Univ. of Science and Technology (China)

\section{Part Two}

$81941 Z$ The research of real time auto-recognition of the moire fringe [8194-71] M. Wang, Z. Wu, Changchun Institute of Optics, Fine Mechanics and Physics (China)

819420 Design considerations and detection capability verification of an imaging Thomson scattering system based on an IEMCCD [8194-72]

X. Xi, J. Zhao, Institute of Plasma Physics (China); S. Kado, The Univ. of Tokyo (Japan);

Q. Zang, X. Han, X. Dai, J. Yang, M. Li, C. Shao, Institute of Plasma Physics (China)

819421 Smear radiometric correction algorithm in star images based on kernel density estimation [8194-73]

J. Gao, Z. Zhang, R. Yao, J. Sun, Y. Zhang, Northwestern Polytechnical Univ. (China)

819422 Experimental study for the effects of stellar spectrums on the location accuracy of a star sensor [8194-74]

Z. Wu, J. Yang, National Univ. of Defense Technology (China); D. Su, Naval Aeronautical and Astronautical Univ. (China)

819423 High accuracy ground target location using loitering munitions platforms [8194-75]

Z. Wang, H. Wang, J. Han, Beijing Univ. of Aeronautics \& Astronautics (China)

819424 A measurement error evaluation method of videometrics [8194-76]

J. Zhou, Y. XU, Y. Shang, National Univ. of Defense Technology (China) and Hunan Key Lab. of Videometrics and Vision Navigation (China)

819425 Technology research of high-definition CCD camera Based on FPG [8194-77] Y. Tian, J. Cao, D. Yao, Z. XU, J. Huang, Xi'an Institute of Optics and precision Mechanics (China)

819426 3D hand and palmprint acquisition using full-field composite color fringe projection [8194-78]

H. Feng, Z. Wang, Hebei Univ. of Technology (China); D. Kuang, Nankai Univ. (China);

Z. Zhang, S. Zhang, Hebei Univ. of Technology (China)

819427 New close-range photogrammetry method based on grain-lacking object [8194-79] $X$. Yang, Z. Li, Surveying and Mapping Institute (China)

819428 A 3D polarizing display system base on backlight control [8194-80]

P. Liu, Z. Huang, Univ. of Electronic Science and Technology of China (China)

819429 An anti-disturbing real time pose estimation method and system [8194-81]

J. Zhou, X. Zhang, National Univ. of Defense Technology (China) and Hunan Key Lab. of Videometrics and Vision Navigation (China)

8194 2A Rapid fabrication of lightweight SiC mirror using CCOS [8194-82]

H. Zhu, X. Liu, D. Yan, P. Ma, Chengdu Fine Optical Engineering Research Ctr. (China) 
$81942 \mathrm{~B}$ The simple model of large scale co-ordinate measuring system and its error analysis [8194-83]

H. Cai, W. Zhu, K. Li, Beijing Institute of Technology (China); M. Liu, Beijing Institute of Technology (China) and Beijing Technology and Business Univ. (China)

$81942 \mathrm{C}$ The report on performance of image intensifier affected by gas on surface [8194-84] L. Yan, F. Shi, Y. Cheng, H. Cheng, H. Shi, Z. Hou, F. Liu, North Night Vision Technology Group Co., Ltd. (China)

8194 2D X-ray compound refractive lens made of Al Mg and Si [8194-85] Q. Jian, W. Peng, Shenzhen Univ. (China)

$81942 \mathrm{E} \quad$ A high-speed image acquisition and processing system in photoelectric tracking [8194-86] L. Qin, Z. Hou, Y. Wu, F. Tan, F. He, Anhui Institute of Optics and Fine Mechanics (China)

$81942 \mathrm{~F}$ Temporal differential CMOS image sensor for low-light and high-speed applications [8194-87]

N. Guan, X. Zhang, Z. Dong, W. Wang, Y. Gui, J. Han, Y. Wang, B. Huang, H. Chen, Institute of Semiconductors (China)

81942 G Readout on the resonant-cavity-enhanced InGaAs/GaAs quantum-dot photodetector [8194-88]

F. Guo, Y. Wang, F. Mao, Z. Zheng, J. Chu, East China Normal Univ. (China)

$81942 \mathrm{H} \quad$ Optical imaging based on compressive sensing [8194-89]

S. Li, C. Ma, A. Xia, Xi'an Institute of Optics and Precision Mechanics (China)

$819421 \quad$ Analysis of speckle-pattern interference fringes for transverse or longitudinal displacement [8194-90]

F. Huo, J. Guo, W. Wang, Changchun Univ. of Science and Technology (China)

$81942 \mathrm{~J} \quad$ Experiment study on compatibility between high performance microchannel plate and gen III image intensifier [8194-91]

S. Liu, Y. Zhu, F. Shi, J. Nie, T. Zhang, X. Liu, N. Zhang, Z. Liu, Y. He, X. Bai, North Night Vision Science \& Technology Group Corp. (China) and National Key Lab. of Science and Technology on low Light Level Night Vision (China); J. Sun, J. Pan, X. Cong, North Night Vision Science \& Technology Group Corp. (China)

$81942 \mathrm{~K} \quad$ Fusing edges and feature points for robust target tracking [8194-92]

W. Li, Shenyang Institute of Automation (China) and Graduate School of the Chinese Academy of Sciences (China) and Key Lab. Opto-Electronic Information Processing (China); Z. Shi, Shenyang Institute of Automation (China) and Key Lab. Opto-Electronic Information Processing (China); J. Yin, Q. Ding, Research Institute of General Development and Demonstration of Equipment (China)

$81942 \mathrm{~L}$ Performance simulation of reflection-mode GaAs photocathodes with back-interface recombination [8194-93]

J. Zou, East China Institute of Technology (China) and Nanjing Univ. of Science and Technology (China); W. Deng, L. Feng, East China Institute of Technology (China); B. Chang, Nanjing Univ. of Science and Technology (China) 
$81942 \mathrm{M}$ 3D information extraction based on a novel x-ray imaging system [8194-94]

C. YU, Peking Univ. Shenzhen Graduate School (China) and Nanjing Univ. of Posts and Telecommunication (China); L. Kong, Shenzhen Invengo Information Technology Co., Ltd. (China); J. Zhang, Nanjing Univ. of Science and Technology (China); S. Zhang, Peking Univ. Shenzhen Graduate School (China)

$81942 \mathrm{~N}$

Design and characterization of radiation tolerant CMOS image sensor for space applications [8194-95]

X. Wang, J. Bogaerts, W. Ogiers, G. Beeckman, G. Meynants, CMOSIS N.V. (Belgium)

819420 Gain and noise analysis of an intensified EMCCD [8194-96]

X. Xi, J. Zhao, Q. Zang, X. Han, X. Dai, J. Yang, L. Zhang, M. Li, Institute of Plasma Physics (China)

$81942 \mathrm{P} \quad$ Precise motion compensation based on weighted sub-pixel image matching [8194-97] G. Han, Changchun Institute of Optics, Fine Mechanics and Physics (China)

$81942 \mathrm{Q}$ The influence of barrier on dielectric barrier discharge [8194-98]

Y. Wang, Z. Yin, M. Huang, J. Wan, North China Electric Power Univ. (China)

$81942 R \quad$ Theodolite-camera videometrics system based on total station [8194-99]

Z. Zhu, Y. Yuan, X. Zhang, National Univ. of Defense Technology (China) and Hunan Key Lab. of Videometrics and Vision Navigation (China)

$819425 \quad$ Camera calibration method based on circular ring [8194-100]

Y. Yuan, Z. Zhu, Y. Gui, T. Xie, National Univ. of Defense Technology (China) and Hunan Key Lab. of Videometrics and Vision Navigation (China)

8194 2T A new mosaic method for three-dimensional surface [8194-101] Y. Yuan, Z. Zhu, Y. Ding, National Univ. of Defense Technology (China) and Hunan Key Lab. of Videometrics and Vision Navigation (China)

$81942 \mathrm{U}$ Methods of reducing TDM crosstalk in an inline FBG based Fabry-Perot sensor [8194-102] Y. Lu, Z. Meng, National Univ. of Defense Technology (China)

$81942 \mathrm{~V}$ The research on a novel type of the solar-blind UV head-mounted displays [8194-103] S. Zhao, North China Electric Power Univ. (China)

$81942 \mathrm{~W}$ Spectral response and SNR analysis of an Offner imaging spectrometer [8194-104] Z. Wu, X. Du, Univ. of Science and Technology of China (China); Z. Ma, W. Huang, National Engineering Research Ctr. for Information Technology in Agriculture (China); Q. Wang, Univ. of Science and Technology of China (China)

$81942 \mathrm{X}$ Weak-light automatic readout collection and display on the resonant-cavity-enhanced quantum dot photoelectric sensor [8194-105]

F. M. Guo, H. You, W. Q. Gu, D. D. Han, Z. Q. Zhu, East China Normal Univ. (China)

$81942 Y$ Research on high accuracy diameter measurement system with CCD [8194-106] B. Su, Beijing Key Lab. for Terahertz Spectroscopy and Imaging (China) and Capital Normal Univ. (China); G. Duan, Beijing Institute of Technology (China) 
$81942 Z$ The optimization of noise and dynamic range with variable-gain column amplifier in CMOS image sensors [8194-107]

R. Deng, J. Yu, Y. Chen, Shanghai Institute of Technical Physics (China)

819430 A study on the buffeting aberrance regulation of TDICCD mapping camera [8194-108] Z. Bai, Xi'an Institute of Optics and Precision Mechanics (China) and Graduate Academy of China Association of Science (China); Z. Ma, B. Zhang, Xi'an Institute of Optics and Precision Mechanics (China)

819431 In-orbit performance calibration method of imaging satellites based on stars [8194-109] Y. Yuan, Y. Zhang, Z. Yin, Shanghai Engineering Ctr. for Micro-satellites (China) and Shanghai Institute of Micro-system and Information Technology (China)

819432 Integrated solution for high resolution CCD camera imaging circuits [8194-110]

Z. Bai, Xi'an Institute of Optics and Precision Mechanics (China) and Graduate Academy of China Association of Science (China); Y. XU, Sichuan Univ. (China); B. Zhang, K. Duan, Xi'an Institute of Optics and Precision Mechanics (China)

819433 A high-speed CMOS image sensor with column-parallel single capacitor CDSs and single-slope ADCs [8194-111]

Q. Li, C. Shi, N. Wu, Institute of Semiconductors (China)

819434 Depth map resolution enhancement for 2D/3D imaging system via compressive sensing [8194-112]

J. Han, O. Loffeld, K. Hartmann, Univ. Siegen (Germany)

819435 Image lag optimization of four-transistor pixel for high speed CMOS image [8194-113]

Y. Zhou, Z. Cao, Q. Li, Q. Qin, N. Wu, Institute of Semiconductors (China)

819436 Research on UV detector technology and application in MAWS [8194-114]

D. Yao, W. Hao, X. Yang, Y. Tian, Xi'an Institute of Optics and Precision Mechanics (China)

819437 Study of MBE growth for extended blue photocathode window layer [8194-115]

G. Jiao, Science and Technology on Low-Light-Level Night Vision Lab. (China) and North Night Vision Technology Group Co., Ltd (China) and Northwestern Polytechnical Univ. (China); F. Shi, C. Hu, Science and Technology on Low-Light-Level Night Vision Lab. (China) and North Night Vision Technology Group Co., Ltd (China); W. Wang, Beijing National Lab. for Condensed Matter Physics (China); W. Cheng, X. XU, Science and Technology on Low-Light-Level Night Vision Lab. (China) and North Night Vision Technology Group Co., Ltd (China)

819438 Visibility enhancement for robust tracking under bad weather [8194-116]

S. Kang, W. Bo, Beijing Institute of Technology (China)

8194 3A Development of a near infrared image intensifier using a generation III configuration [8194-118]

B. Ren, F. Shi, H. Cheng, H. Liv, L. Feng, L. Zhang, Z. Miao, North Night Vision Technology

Group Co., Ltd (China) 
8194 3B Design of image stabilization system for space remote sensor based on DaVinci technology [8194-119]

H. Li, Z. Liu, P. Xu, Beijing Institute of Space Mechanics \& Electricity (China)

$81943 \mathrm{C}$ Statistical analyses of noise in photon imaging detection system [8194-120]

Y. Huang, X. Zhang, X. Yu, Beijing Institute of Technology (China)

8194 3D Study on transient noise of CCD camera induced by Y-ray [8194-121]

B. Duan, D. Hei, G. Song, J. Ma, Z. Zhang, C. Han, Y. Song, M. Zhou, L. Lei, Northwest Institute of Nuclear Technology (China)

$81943 \mathrm{E} \quad$ Studying on red edge characteristics of maize leaf using visible /near-infrared imaging hyperspectra [8194-122]

D. Zhang, Q. Liao, Beijing Research Ctr. for Information Technology in Agriculture (China) and Zhejiang Univ. (China); L. Huang, J. Zhao, S. Du, Beijing Research Ctr. for Information Technology in Agriculture (China); Z. Ma, Beijing Research Ctr. for Information Technology in Agriculture (China) and Beijing Research Ctr. for Agri-food Testing and Farmland Monitoring (China)

8194 3F Fluid flow and heat transfer in Joule-Thomson coolers coupled with infrared detectors [8194-123]

B. Du, W. Jia, Luoyang Opto-electro Technology Development Ctr. (China)

8194 3G 3D shape measurement based on Hilbert transform [8194-124]

F. Wang, Y. Xie, J. Guo, Z. Yin, L. Chen, Gannan Normal Univ. (China)

$81943 \mathrm{H}$ The computer scene generation for star simulator hardware-in-the-loop simulation [8194-125]

Y. Zhang, H. Yu, H. Du, J. Lei, Beijing Simulation Ctr. (China)

8194 3L Image noise removal using Kalman-Filter on dark frame [8194-129]

T. Liu, J. Zhao, H. Feng, Z. Xu, H. Chen, Zhejiang Univ. (China)

$81943 \mathrm{M}$ Detection technology of simultaneous imaging polarization [8194-130]

C.-J. Yang, S. Li, Z.-W. Qiu, J. Hong, Y.-L. Qiao, Anhui Institute of Optical and Fine Mechanic (China)

Author Index 
Proc. of SPIE Vol. $8194819401-14$

Downloaded From: https://www.spiedigitallibrary.org/conference-proceedings-of-spie on 26 Apr 2023 Terms of Use: https://www.spiedigitallibrary.org/terms-of-use 


\title{
Symposium Committee
}

\author{
Symposium Chairs
}

Guofan Jin, Tsinghua University (China)

Liwei Zhou, Beijing Institute of Technology (China)

Jingshan Jiang, Center for Space Science and Applied Research (China)

Jianquan Yao, Tianjin University (China)

Shouhuan Zhou, North China Research Institute of Electro-optics

(China)

Lianghui Chen, Institute of Semiconductors (China)

Dianyuan Fan, Shanghai Institute of Optics and Fine Mechanics (China)

Junhao Chu, Shanghai Institute of Technical Physics (China)

Qifeng Yu, National University of Defense Technology (China)

Erqi Liu, Academy of Chinese Aerospace Science and Industry Feihang Technology (China)

\section{Organizing Committee}

Jinxue Wang, Chair, Raytheon Vision Systems (United States)

Yuping Cui, Chair, Academy of Chinese Aerospace Science and Industry Feihang Technology (China)

Zhixin Wu, Chair, Tianjin Jinhang Institute of Technical Physics (China)

Xiaopeng Wang, Chair, Xi'an Institute of Applied Optics (China)

Weibiao Chen, Shanghai Institute of Optics and Fine Mechanics (China)

Haimei Gong, Shanghai Institute of Technical Physics (China)

Yuelin Wang, State Key Laboratory of Transducer Technology (China)

Zhaojun Liu, Beijing Institute of Space Mechanics and Electricity (China)

Bo Liu, Beijing Huahang Radio Measurement and Research Institute (China)

Nianjiang Chen, North China Research Institute of Electro-optics (China)

Guangjun Zhang, Beihang University (China)

Jiancheng Fang, Beihang University (China)

Qian Chen, Nanjing University of Science and Technology (China)

Ping Wei, Beijing Institute of Technology (China)

Pu Wang, Beijing University of Technology (China)

Kecong Ai, Xi'an Institute of Applied Optics (China)

Heguang Liu, Key Laboratory of Microwave Remote Sensing (China)

Jindong Fei , Beijing Simulation Center (China) 
Program Committee

Guofan Jin, Chair, Tsinghua University (China)

Jingshan Jiang, Chair, Center for Space Science and Applied Research (China)

Jianquan Yao, Chair, Tianjin University (China)

Junhao Chu, Chair, Shanghai Institute of Technical Physics (China)

Qifeng Yu, Chair, National University of Defense Technology (China)

Zhihong Wang, North Night Vision Technology Company, Ltd. (China)

Yuelin Wang, State Key Laboratory of Transducer Technology (China)

Pu Wang, Beijing University of Technology (China)

Jin Lu, Tianjin Jinhang Institute of Technical Physics (China)

Kecong Ai, Xi' an Institute of Applied Optics (China)

Feng Liu, Tianjin Jinhang Institute of Technical Physics (China)

Nanjian Wu, Institute of Semiconductors (China)

Guangjun Zhang, Beijing University of Aeronautics and Astronautics (China)

Cunlin Zhang, Capital Normal University (China)

Jianfeng Yang, Xi'an Institute of Optics and Precision Mechanics (China)

Weibiao Chen, Shanghai Institute of Optics and Fine Mechanics (China)

Qian Chen, Nanjing University of Science and Technology (China)

Jiancheng Fang, Beijing University of Aeronautics and Astronautics (China)

Chunqing Gao, Beijing Institute of Technology (China)

Haimei Gong, Shanghai Institute of Technical Physics (China)

Rong Shu, Shanghai Institute of Technical Physics (China)

Tianyu Xie, Peking University (China) 


\title{
Conference Committee
}

\author{
Conference Chairs \\ Makoto Ikeda, University of Tokyo (Japan) \\ Nanjian Wu, Institute of Semiconductors (China) \\ Guangjun Zhang, Beijing University of Aeronautics and Astronautics \\ (China) \\ Kecong Ai, Science and Technology on Low Light Level Night Vision \\ Laboratory (China)
}

Program Committee

Masayuki Ikebe, Hokkaido University (Japan)

Hoi-Jun Yoo, Korea Advanced Institute of Science and Technology (Republic of Korea)

W. Du, Shizuoka University (Japan)

Ivan Prochazka, Czech Technical University (Czech)

Libin Yao, Kunming Institute of Physics (China)

Kun Zhang, The 44th Institute of China Electronic Technology Group Corporation (China)

Qiaolin Huang, Beijing Institute of Space Mechanics and Electricity (China)

Zhihong Wang, North Night Vision Technology Co., Ltd (China)

Binqiao Li, Tianjin University (China)

Xiangliang Jin, Xiang Tan University (China)

Weiqi Jin, Beijing Institute of Technology (China)

Yan Zhou, Institute of Semiconductors (China)

Huandong Zheng, Tianjin Jingang Institute of Technical Physics (China) 
Proc. of SPIE Vol. $8194819401-18$

Downloaded From: https://www.spiedigitallibrary.org/conference-proceedings-of-spie on 26 Apr 2023 Terms of Use: https://www.spiedigitallibrary.org/terms-of-use 


\section{Introduction}

We have had the great honor to organize the 4th International Symposium on Photoelectronic Detection and Imaging in Beijing; it follows ISPDI2009 held also in Beijing in 2009. More than 1000 participants attended ISPDI 2011. The symposium provided a forum for the participants to report and review ideas and up-to-date comprehensive progress and developments and to discuss the novel approaches to application areas in the field of photoelectronic detection and imaging.

There were 720 papers accepted for presentation at ISPDI 2011, contributed by over 1,200 authors from nearly 20 countries, including: United States, Canada, Russia, United Kingdom, Germany, Ireland, Belgium, Poland, Czech Republic, South Africa, Australia, Korea, Japan, India, Malaysia, Singapore, China, and so on. We have nearly 100 international famous scientists and experts as invited speakers. The invited papers covered topics such as sensor and micromachined optical device technologies, laser sensing and imaging, infrared imaging and applications, imaging detector and applications, terahertz wave technologies and applications, space exploration technologies and applications, and related technologies and applications. It is sincerely hoped that the research and development in photoelectronic detection and imaging will be promoted, and the international cooperation sharing the common interest will be enhanced.

I would like to heartily to thank our sponsors and cooperative organizations for all they have done for the symposium. Thanks also to all the authors for their contributions to these proceedings, to all of the participants and friends for their interest and efforts in helping to make the symposium possible, to the organizing committee and the program committee for their effective work an valuable advice, especially the ISPDI2011 Secretariat, and to the SPIE staff for their tireless effort and outstanding service in preparing and publishing the conference proceedings.

Again, we extend our warmest greetings to you and hope you have had a rewarding and exciting stay during ISPDI 2011.

Guofan Jin 
Proc. of SPIE Vol. $8194819401-20$

Downloaded From: https://www.spiedigitallibrary.org/conference-proceedings-of-spie on 26 Apr 2023 Terms of Use: https://www.spiedigitallibrary.org/terms-of-use 


\title{
Local Cooperating Organizations of ISPDI 2011
}

\author{
Shanghai Institute of Optics and Fine Mechanics, CAS (China) \\ Shanghai Institute of Technical Physics, CAS (China) \\ Beijing Institute of Space Mechanics and Electricity (China) \\ Beijing Huahang Radio Measurement and Research Institute (China) \\ North China Research Institute of Electro-optics (China) \\ Beijing University of Aeronautics and Astronautics (China) \\ Nanjing University of Science and Technology (China) \\ Beijing Institute of Technology (China) \\ Beijing University of Technology (China) \\ State Key Laboratory of Transducer Technology (China) \\ Science and Technology on Micro-system Laboratory (China) \\ The Key Laboratory of Microwave Remote Sensing, CAS (China) \\ Science and Technology on Space System Simulation Laboratory, Beijing \\ Simulation Center (China)
}


Proc. of SPIE Vol. $8194819401-22$

Downloaded From: https://www.spiedigitallibrary.org/conference-proceedings-of-spie on 26 Apr 2023 Terms of Use: https://www.spiedigitallibrary.org/terms-of-use 